\title{
Effect of growth-promoting technologies on Longissimus lumborum muscle fiber morphometrics, collagen solubility, and cooked meat tenderness ${ }^{1,2}$
}

\author{
S. M. Ebarb,* J. S. Drouillard,* K. R. Maddock-Carlin, † K. J. Phelps,* M. A. Vaughn,* \\ D. D. Burnett,* C. L. Van Bibber-Krueger,* C. B. Paulk, \$ D. M. Grieger,* and J. M. Gonzalez*3 \\ *Department of Animal Sciences and Industry, Kansas State University, Manhattan 66506; $\dagger$ Department of Animal \\ Sciences, North Dakota State University, Fargo 58102; and Department of Animal Science, Texas A\&M University, \\ College Station 77840
}

\begin{abstract}
The objective of the study was to examine the effect of growth-promoting technologies (GP) on Longissimus lumborum steak tenderness, muscle fiber cross-sectional area (CSA), and collagen solubility. Crossbred feedlot heifers $(n=33$; initial BW $464 \pm 6 \mathrm{~kg})$ were blocked by BW and assigned to 1 of 3 treatments: no GP (CON; $n=11)$; implant, no zilpaterol hydrochloride (IMP; $n=11$ ); implant and zilpaterol hydrochloride (COMBO; $n=11)$. Heifers assigned to receive an implant were administered Component TE-200 on d 0 of the study, and the COMBO group received $8.3 \mathrm{mg} /$ $\mathrm{kg}$ DM of zilpaterol hydrochloride for the final $21 \mathrm{~d}$ of feeding with a $3 \mathrm{~d}$ withdrawal period. Following harvest, strip loins were collected and fabricated into 4 roasts and aged for 3, 14, 21, or $35 \mathrm{~d}$ postmortem. Fiber type was determined by immunohistochemistry. After aging, objective tenderness and collagen solubility were measured. There was a treatment $\times$ day of aging $(\mathrm{DOA})$ interaction for Warner-Bratzler shear force (WBSF; $P<$ $0.01)$. At $\mathrm{d} 3$ of aging, IMP and COMBO steaks had greater WBSF than CON steaks $(P<0.01)$. By d 14 of aging, the WBSF of IMP steaks was not different $(P=$ $0.21)$ than CON steaks, but COMBO steaks had greater
\end{abstract}

shear values than steaks of other treatments $(P<0.02)$. The COMBO steaks only remained tougher $(P=0.04)$ than the CON steaks following 35 DOA. Compared to CON muscles, IMP and COMBO type I and IIX muscle fibers were larger $(P<0.03)$. Treatment, DOA, or the two-way interactions did not impact measures of total and insoluble collagen $(P>0.31)$. Soluble collagen amount tended to be affected $(P=0.06)$ by a treatment $\times$ DOA interaction which was due to COMBO muscle having more soluble collagen than the other 2 treatments on $\mathrm{d} 21$ of aging $(P<0.02)$. Correlation analysis indicated that type I, IIA, and IIX fiber CSA are positively correlated with WBSF at $\mathrm{d} 3$ and 14 of aging $(P<0.01)$, but only type IIX fibers are correlated at d 21 and 35 of aging $(P<0.03)$. At these time periods, total and insoluble collagen became positively correlated with WBSF $(P<0.01)$. This would indicate that relationship between muscle fiber CSA and WBSF decreases during postmortem aging, while the association between WBSF and collagen characteristics strengthens. The use of GP negatively impacted meat tenderness primarily through increased muscle fiber CSA and not through altering collagen solubility.

Key words: collagen, fiber cross-sectional area, growth promotants, tenderness

\section{INTRODUCTION}

In beef cattle production, anabolic implants and beta-adrenergic agonists (B-AA) are the 2 most commonly employed growth-promoting technologies (GP). Duckett and Pratt (2014) conducted a comprehensive review of the literature and reported that implants can increase ADG by $18 \%$, carcass weight by $5 \%$, and ribeye area by $4 \%$. Lean et al. (2014) conducted a metaanalysis of the available B-AA data and reported that 
zilpaterol hydrochloride (ZH; Merck Animal Health, Summit, NJ) increases ADG by $0.15 \mathrm{~kg}$, carcass weight by $15 \mathrm{~kg}$, and ribeye area by $8 \mathrm{~cm}^{2}$. While the positive impacts of both GP on feedlot performance and carcass measures are quite considerable, both technologies can have a negative impact on meat tenderness. Boles et al. (2009) reported anabolic implants increased heifer Warner-Bratzler shear force (WBSF) by 9\%, while Leheska et al. (2009) reported ZH increased heifer WBSF by values by $24 \%$. The exact biological mechanisms responsible for the reduction in tenderness is unknown.

Two major structural units of muscle elicit the majority of the influence on meat tenderness. The muscle fiber constitutes the major component of the myofibrillar fraction of tenderness and can elicit its influence based on fiber size (Crouse et al., 1991) or sarcomere length (Smulders et al., 1990). Collagen is the major component of the endomysium and perimysium, which both comprise the intramuscular connective tissue component that contribute to meat tenderness and texture (McCormick, 1999). Both GP increase muscle fiber hypertrophy (Kellermeier et al., 2009), but their effect on the collagen component is not well understood. Additionally, the ability of extended postmortem aging to reduce the impact that both structures elicit on meat tenderness of GP treated cattle is not known. The objective of the study was to examine the effect of 2 GP programs on Longissimus lumborum (LL) muscle fiber cross-sectional area, collagen solubility, and their relation to meat tenderness after extended aging.

\section{MATERIAL AND METHODS}

All experimental procedures were approved by the Kansas State University Institutional Animal Care and Use Committee.

\section{Heifer Management}

Thirty- three crossbred feedlot heifers (initial BW $464 \mathrm{~kg} \pm 6$ ) were housed in individual pens located in an enclosed barn at the Kansas State University Beef Cattle Research Center. Each pen was $4.64 \mathrm{~m}^{2}$ and contained metal pipe sidewalls, slatted floors for waste removal, an individual waterer, and a $75 \mathrm{~cm} \times 51$ $\mathrm{cm}$ feed bunk. Heifers were fed a similar diet (Table 1) and feed was delivered once daily to allow ad libitum access to feed. Bunks were managed to leave a minimum of $227 \mathrm{~g}$ of unconsumed feed per head daily.

Following a 10-d acclimation period, heifers were weighed, stratified from heaviest to lightest BW, and within each strata of 3 animals, heifers were randomly allocated to 1 of 3 treatments $(n=11$ per treatment): no anabolic implant or ZH (CON), anabolic implant, no
Table 1. Diet composition (DM basis) for crossbred heifers subjected to 3 exogenous growth-promoting programs

\begin{tabular}{lrcc}
\hline \hline & \multicolumn{3}{c}{ Treatment } \\
\cline { 2 - 4 } Ingredient & $\mathrm{CON}^{1}$ & $\mathrm{IMP}^{1}$ & $\mathrm{COMBO}^{1}$ \\
\hline Steam-flaked corn, \% & 52.70 & 52.70 & 52.70 \\
Corn gluten feed, \% & 36.15 & 36.15 & 36.15 \\
Ground alfalfa hay, \% & 3.87 & 3.87 & 3.86 \\
Ground wheat straw, \% & 2.95 & 2.95 & 2.95 \\
Mineral/vitamin supplement, \% & & & \\
Ground limestone, \% & 1.55 & 1.55 & 1.55 \\
Salt, \% & 0.29 & 0.29 & 0.29 \\
Potassium chloride, \% & 0.20 & 0.20 & 0.20 \\
Vitamin A 30,000 premix, \% & 0.006 & 0.006 & 0.006 \\
Vitamin E 44,092 premix, \% & 0.09 & 0.09 & 0.09 \\
Monensin and tylosin premix, $\%$ & 2.16 & 2.16 & 2.16 \\
Calculated nutrient composition & & & \\
NEm, Mcal/kg & 0.95 & 0.95 & 0.95 \\
NEg, Mcal/kg & 0.65 & 0.65 & 0.65 \\
ADF, \% & 9.00 & 9.00 & 9.00 \\
NDF, \% & 21.46 & 21.46 & 21.46 \\
CP, \% & 14.56 & 14.56 & 14.56 \\
Ether extract, \% & 3.60 & 3.60 & 3.60 \\
Ca, \% & 0.69 & 0.69 & 0.69 \\
P, \% & 0.52 & 0.52 & 0.52 \\
K, \% & 0.80 & 0.80 & 0.80 \\
Vitamin A (added), IU/kg & 0.98 & 0.98 & 0.98 \\
Vitamin E (added), IU/kg & 19.67 & 19.67 & 19.67 \\
\hline & & & \\
\hline
\end{tabular}

${ }^{1}$ Crossbred feedlot heifers $(n=32)$ were subjected to 1 of 3 treatments: no implant or zilpaterol hydrochloride (CON); Component TE-200 implant (Elanco Animal Health, Greenfield, IN) on d 0 of study, no zilpaterol hydrochloride (IMP); and Component TE-200 implant on d 0 of study and zilpaterol hydrochloride (Merck Animal Health, Summit, NJ) at $8.3 \mathrm{mg} / \mathrm{kg}$ of $\mathrm{ZH}$ from d 50 to d 71, followed by a 3-d withdrawal (COMBO).

${ }^{2}$ Formulated to provide $300 \mathrm{mg} /$ day monensin and $90 \mathrm{mg} /$ day tylosin (Elanco Animal Health) per animal in a ground corn carrier.

ZH (IMP), and anabolic implant and ZH (COMBO). Heifers designated to receive anabolic implants were administered a Component TE-200 implant (Elanco Animal Health, Greenfield, IN) in the left ear. Beginning on $\mathrm{d} 50$ of the trial, $\mathrm{ZH}$ was included in the total mixed ration at the approved level of $8.3 \mathrm{mg} / \mathrm{kg}$ $\mathrm{DM}$ for the COMBO heifers. These cattle were fed $\mathrm{ZH}$ for $21 \mathrm{~d}$ with a $3-\mathrm{d}$ withdrawal period prior to harvest. One heifer from the IMP treatment was removed from study due to pregnancy.

\section{Carcass Data and Loin Collection}

On d 75 of feeding, heifers were shipped $430 \mathrm{~km}$ to a commercial abattoir for harvest (Tyson Fresh Meats, Holcomb, KS). Final BW and HCW were recorded at harvest. Following a 36-h refrigeration period, marbling score, LM area, and 12th-rib s.c. fat thickness (BF) were instrumentally collected (VBG 2000; e+v 
Technology GmbH \& Co. KG, Oranienburg, Germany), and percent $\mathrm{KPH}$ was estimated by a trained university staff member. Strip loins (Institutional Meat Purchase Specifications 180) were removed from the right side of the carcass from each heifer and transported back to the Kansas State University Meats Laboratory.

\section{Sampling Procedures}

Approximately $72 \mathrm{~h}$ postmortem, a $1.27-\mathrm{cm}$ thick steak was removed from the anterior portion of the LL, beginning at the 13th rib of each loin, and perpendicular to the orientation of muscle fibers for immunohistochemistry. At the posterior end of the loin, $\mathrm{pH}$ was measured with a calibrated $\mathrm{pH}$ meter (model HI 99163; Hanna Instruments, Smithfield, RI). The remaining portion of each loin was fabricated into four $5.08-\mathrm{cm}$ thick roasts and assigned in order of fabrication to 3, 14, 21, or $35 \mathrm{~d}$ of aging (DOA). All roasts were vacuum packaged in 3 mil standard barrier vacuum bags with oxygen transmission rates of $4.5 \mathrm{~cm}^{3} \cdot 100 \mathrm{~cm}^{-2} \cdot 24 \mathrm{~h}^{-1}$ at $23^{\circ} \mathrm{C}$ and $65 \%$ humidity (Prime Source Vacuum Pouches; Bunzl Processor Division, Koch Supplies, Kansas City, $\mathrm{MO}$ ) and aged at $2 \pm 1^{\circ} \mathrm{C}$. After each aging period was completed, one 2.54-cm steak was removed for collagen crosslink and calpain analysis (Howard et al., 2015), while the other steak was utilized for Warner-Bratzler shear force analysis. Following 21-d aging period, the remaining portion of the loin following fabrication was utilized to measure $\mathrm{pH}$ after postmortem aging.

\section{Immunohistochemistry}

The methods of Phelps et al. (2014a) were followed for immunohistochemical analysis. Briefly, a $1 \mathrm{~cm} \times$ $1 \mathrm{~cm} \times 1.27 \mathrm{~cm}$ sample was collected from the geometric center of the medial (MED), medial/lateral (M/L), and lateral (LAT) areas of the LL. Samples were embedded and frozen in optimum cutting temperature tissue freezing medium (Fisher Scientific, Pittsburgh, PA) using liquid nitrogen cooled, 2-methyl-butane (Fisher Scientific). Five micrometer cryosections were blocked with $10 \%$ horse serum and $0.2 \%$ TritonX-100 in PBS and then incubated for $1 \mathrm{~h}$ in a primary antibody cocktail consisting of rabbit anti-dystrophin (Thermo Scientific, Waltman, MA), mouse anti-slow myosin heavy chain (BA-D5, Developmental Studies Hybridoma Bank, Iowa City, IA), and mouse anti-myosin heavy chain all but IIX (BF-35, Developmental Studies Hybridoma Bank). Following washing and incubation with the appropriate secondary antibodies (Alexa-Fluor 594, 633, and 488; Invitrogen, Grand Island, NY), photomicrographs were captured using a Nikon Eclipse TI-U inverted microscope equipped with a DS-QiMC digital camera at a $10 \times$ working dis- tance magnification (Nikon Instruments Inc., Melville, NY). Within each steak location, a minimum of 500 muscle fibers were analyzed for myosin heavy chain isoform and CSA. Fibers staining positive for BA-D5 and BF-35 were considered type I fibers. Fibers staining positive for BF-35, but negative for BA-D5 were considered type IIA fibers. All fibers staining negative for BA-D5 and BF-35 were considered type IIX fibers (Fig. 1).

\section{Warner-Bratzler Shear Force}

After each aging period, steaks were immediately subjected to cooking procedures. Cooking procedures for WBSF were conducted according to the Meat Cookery and Sensory Guidelines (AMSA, 1995). External fat was removed and steaks were weighed prior to cooking. A thermocouple wire (30-gauge copper and constantan; Omega Engineering, Stamford, CT) was inserted into the geometric center of each steak and internal temperature was monitored using a Doric Minitrend 205 monitor (VAS Engineering, San Francisco, CA). Steaks were cooked on Hamilton Beach Indoor/Outdoor grills (Hamilton Beach, Southern Pines, NC), turned once at $40^{\circ} \mathrm{C}$ and removed at $70^{\circ} \mathrm{C}$. Steaks were allowed to cool at room temperature for approximately $10 \mathrm{~min}$, then weighed for calculation of cooking loss. After a 24-h chill period at $7 \pm 1^{\circ} \mathrm{C}$, two 1.27 -cm cores were removed from each anatomical area within the steak parallel to the muscle fiber orientation. Each core was sheared once through the center with a Warner-Bratzler shear head (100 kg compression load cell, crosshead speed of $250 \mathrm{~mm} / \mathrm{min}$ ) attached to an INSTRON testing machine (Model 5569; Instron, Canton, MA).

\section{Collagen Solubility}

After aging, each steak for collagen analysis was cut into the 3 areas of interest, frozen in liquid nitrogen, pulverized using a Waring blender (Waring Products Division, Harford, CT), and stored at $-20^{\circ} \mathrm{C}$ until analysis. Hydroxyproline content was determined using the protocol adapted from Hill (1966) and Association of Official Analytical Chemists method 990.26 (AOAC, 2005). Three grams of pulverized tissue were mixed with $12 \mathrm{~mL}$ of Ringer's solution and incubated in a $77^{\circ} \mathrm{C}$ water bath for $80 \mathrm{~min}$. Following incubation, samples were centrifuged at $2,250 \times \mathrm{g}$ for $12 \mathrm{~min}$ at $20^{\circ} \mathrm{C}$ to separate insoluble and soluble fractions. Sulfuric acid was then added ( $3 \mathrm{~mL}$ concentrated sulfuric acid to soluble portion; $30 \mathrm{~mL} 3.5 \mathrm{M}$ sulfuric acid to the insoluble portion) and fractions were incubated at $105^{\circ} \mathrm{C}$ for $16 \mathrm{~h}$. After incubation, samples were removed and cooled for a minimum of $30 \mathrm{~min}$, diluted with deionized water to $250 \mathrm{~mL}$ for the soluble fraction and $500 \mathrm{~mL}$ for 

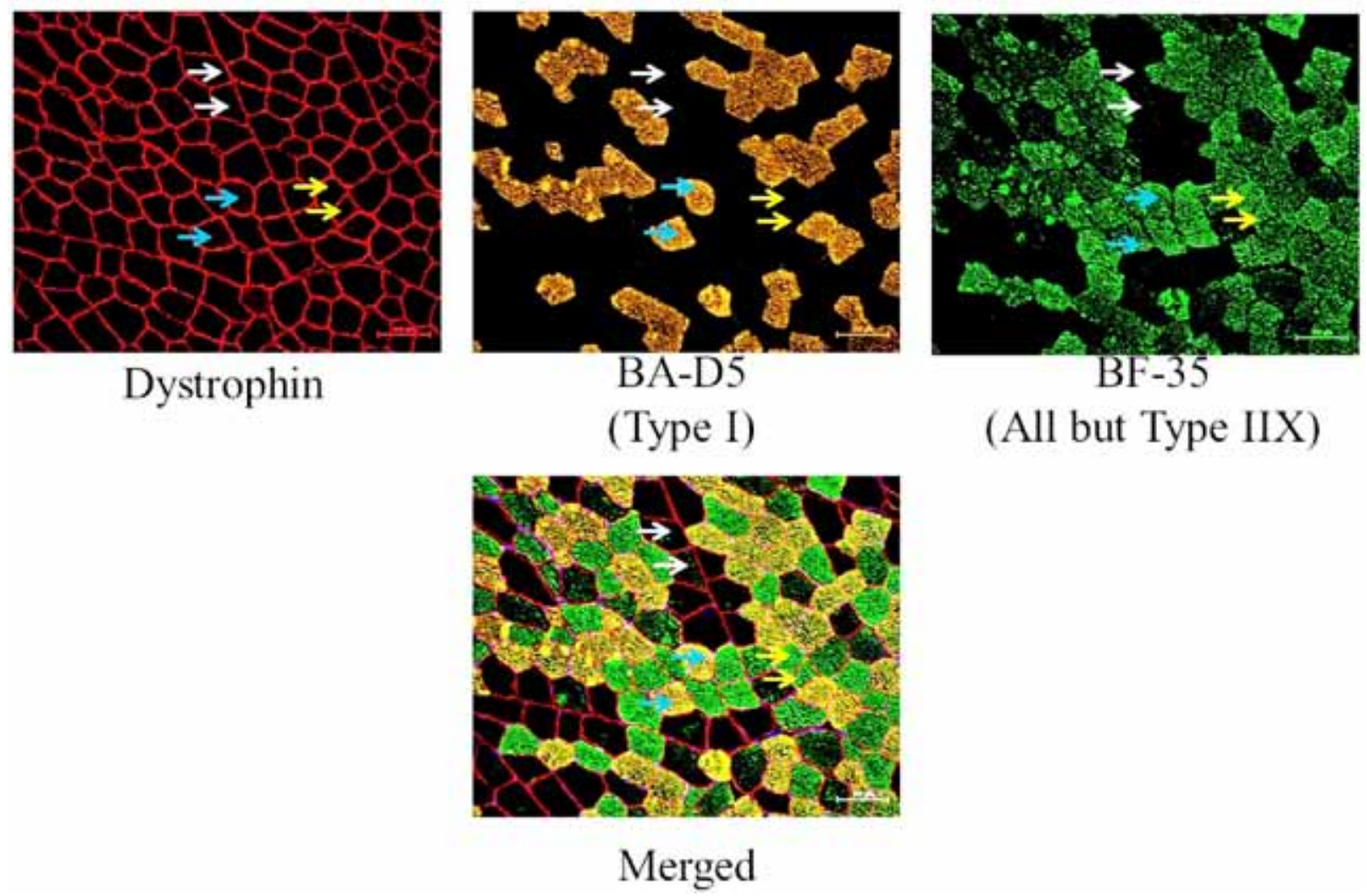

Figure 1. Representative photomicrographs of immunohistological staining pattern of beef Longissimus lumborum muscle. Fibers that stained positive for the BA-D5 antibody were categorized as type I fibers (blue arrows). Fibers that stained positive for BF-35, but were negative for BA-D5, were categorized as type IIA fibers (yellow arrows). All fibers that were negative for the BF-35 antibody were categorized as type IIX fibers (white arrows; Moreno-Sanchez et al., 2008; Schiaffino et al., 1989). Scale bars $=100 \mu \mathrm{m}$.

the insoluble fraction, and then filtered with Whatman 541 filter paper (Fisher Scientific; Waltham, MA) into $15-\mathrm{mL}$ glass test tubes and analyzed using a hydroxyproline assay the same day. Hydroxyproline determination was carried out following procedures outlined by Bergman and Loxley (1963) using a BioTek Eon spectrophotometer (Biotek Instruments Inc., Winooski, VT) to read absorbance at $558 \mathrm{~nm}$. The spectrophotometer was calibrated using a distilled water blank sample, and readings were quantified by standard curves prepared each day of analysis. Total and fractional collagen contents were determined by multiplying hydroxyproline content of the soluble fraction by 7.25 and the insoluble fraction by 7.52 (Cross et al., 1973). Duplicate samples with a CV greater than $10 \%$ were reanalyzed.

\section{Statistical Analysis}

Four statistical models, all utilizing animal as the experimental unit, were employed to analyze these data. All models were randomized complete block designs with initial BW as the blocking factor. Feedlot performance, carcass characteristics, and d 21 moisture loss utilized GP treatment as the fixed effect and BW block as the random effect. Cook loss and $\mathrm{pH}$ data were analyzed as a repeated measures experiment, utilizing GP treatment as the fixed effect and animal within block as the random effect. Day served as the repeated measure with animal/loin as the subject and compound symmetry as the covariance structure. Muscle fiber morphometric data, collagen measures, and WBSF were analyzed as a split-plot design with Animal as the whole-plot unit and the area of the LL as the split-plot unit. The muscle fiber morphometric data was a $3 \times 3$ factorial arrangement with GP treatment and muscle location as the main effects. Collagen measures and WBSF were analyzed as a $3 \times 4 \times 3$ factorial arrangement with GP treatment, day of aging, and muscle location as the main effects. All data were analyzed utilizing the PROC MIXED procedure of SAS (SAS Inst. Inc., Cary, NC) and pairwise comparisons between the least square means of the factor level comparisons were computed using the PDIFF option of the LSMEANS statement. Correlations between WBSF and muscle characteristics were computed using the PROC CORR procedure of SAS. Differences were considered significant at $P \leq 0.05$ and tendencies at $P>0.05$ and $P \leq 0.10$. 
Table 2. Feedlot performance and carcass characteristics of crossbred heifers subjected to 3 exogenous growth-promoting programs

\begin{tabular}{|c|c|c|c|c|c|}
\hline \multirow[b]{2}{*}{ Item } & \multicolumn{3}{|c|}{ Treatment $^{1}$} & \multirow[b]{2}{*}{ SEM } & \multirow[b]{2}{*}{$P$-value } \\
\hline & $\mathrm{CON}$ & IMP & COMBO & & \\
\hline \multicolumn{6}{|l|}{ Live performance } \\
\hline Initial BW, kg & 463.7 & 463.8 & 463.9 & 2.0 & 0.82 \\
\hline Final BW, kg & 530.9 & 541.8 & 541.9 & 6.6 & 0.31 \\
\hline DMI, kg & 8.5 & 8.2 & 8.1 & 0.2 & 0.48 \\
\hline $\mathrm{ADG}, \mathrm{kg}$ & 0.9 & 1.1 & 1.1 & 0.1 & 0.30 \\
\hline $\mathrm{G}: \mathrm{F}$ & 0.11 & 0.13 & 0.13 & 0.01 & 0.06 \\
\hline \multicolumn{6}{|l|}{ Carcass characteristics } \\
\hline $\mathrm{HCW}, \mathrm{kg}$ & $345.9^{\mathrm{a}, \mathrm{x}}$ & $354.4^{\mathrm{a}, \mathrm{b}, \mathrm{y}}$ & $361.9^{\mathrm{b}}$ & 4.1 & 0.01 \\
\hline Dressing percentage, $\%$ & 65.2 & 65.4 & 66.8 & 0.5 & 0.07 \\
\hline USDA yield grade & $3.6^{\mathrm{a}}$ & $2.6^{\mathrm{b}}$ & $2.4^{\mathrm{b}}$ & 0.4 & 0.03 \\
\hline $\mathrm{LM}$ area, $\mathrm{cm}^{2}$ & $78.2^{\mathrm{a}, \mathrm{x}}$ & $88.8^{\mathrm{a}, \mathrm{b}, \mathrm{y}}$ & $92.2^{\mathrm{b}}$ & 3.7 & 0.03 \\
\hline $12^{\text {th }}$-rib s.c. fat, cm & $2.0^{\mathrm{a}, \mathrm{x}}$ & $1.5^{\mathrm{a}, \mathrm{b}, \mathrm{y}}$ & $1.3^{\mathrm{b}}$ & 0.2 & 0.04 \\
\hline $\mathrm{KPH}, \%$ & 2.5 & 2.4 & 2.4 & 0.1 & 0.59 \\
\hline Marbling score ${ }^{2}$ & 610.9 & 534.0 & 560.9 & 23.5 & 0.09 \\
\hline Initial loin weight, $\mathrm{kg}$ & 6.5 & 6.9 & 7.1 & 0.2 & 0.11 \\
\hline
\end{tabular}

${ }^{\mathrm{a}, \mathrm{b}}$ Means within a row with a different superscript are different $(P<0.05)$.

$\mathrm{x}, \mathrm{y}$ Means within a row with a different superscript tend to differ $(P<$ $0.10)$.

${ }^{1}$ Crossbred feedlot heifers $(n=32)$ were subjected to 1 of 3 treatments: no implant or zilpaterol hydrochloride (CON); Component TE-200 implant (Elanco Animal Health, Greenfield, IN) on d 0 of study, no zilpaterol hydrochloride (IMP); and Component TE-200 implant on d 0 of study and zilpaterol hydrochloride (Merck Animal Health, Summit, NJ) at $8.3 \mathrm{mg} / \mathrm{kg}$ of ZH from d 50 to d 71, followed by a 3-d withdrawal (COMBO).

${ }^{2}$ Marbling scores: $500=$ small00; $600=$ modest $00 ; 700=$ moderate 00.

\section{RESULTS}

\section{Heifer Performance and Carcass Characteristics}

Individually fed heifers were subjected to 1 of 3 treatments to determine the effect of GP on feedlot and carcass performance measures. At the beginning of the trial, all treatment groups did not differ in BW $(P=$ 0.82; Table 2). Throughout the 75-d feeding portion of the trial, GP treatment did not impact DMI and ADG $(P>0.30)$. Gain to feed ratio tended to be affected $(P=$ $0.06)$ by GP treatment, but final BW was unaffected $(P=0.48)$ by treatment. The use of GP impacted $(P=$ $0.01) \mathrm{HCW}$. Carcasses from the IMP treatment tended to weigh more $(P=0.07)$ than the CON carcasses, but were not different $(P=0.11)$ than COMBO carcasses. Carcasses from the COMBO treatment were heavier $(P<0.01)$ than CON carcasses. Dressing percentage tended to be influenced $(P=0.07)$, while yield grade was impacted $(P=0.03)$ by GP treatment. The IMP and $\mathrm{COMBO}$ carcasses had decreased yield grade when compared to $\mathrm{CON}$ carcasses $(P<0.04)$, but were not different $(P=0.63)$ from each other. Similar to HCW, GP treatment impacted LM area and 12th-rib s.c. fat $(P<0.04)$. Carcasses from IMP cattle tended
Table 3. Purge and $\mathrm{pH}$ of subprimals and cook loss of steaks from the Longissimus lumborum of heifers subjected to 3 exogenous growth-promoting programs

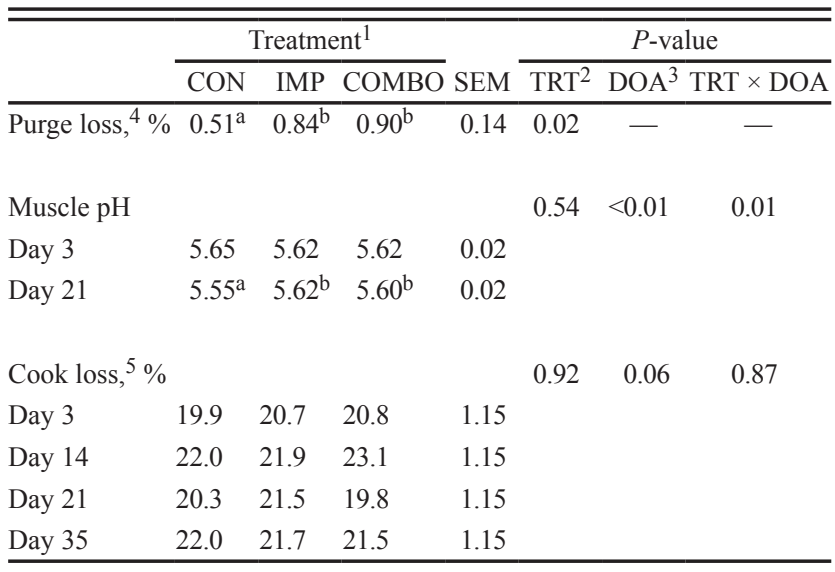

a,b Means within a row with a different superscript are different $(P<0.05)$.

${ }^{1}$ Crossbred feedlot heifers $(n=32)$ were subjected to 1 of 3 treatments: no implant or zilpaterol hydrochloride (CON); Component TE-200 implant (Elanco Animal Health, Greenfield, IN) on d 0 of study, no zilpaterol hydrochloride (IMP); and Component TE-200 implant on $\mathrm{d} 0$ of study and zilpaterol hydrochloride (Merck Animal Health, Summit, NJ) at $8.3 \mathrm{mg} / \mathrm{kg}$ of $\mathrm{ZH}$ from $\mathrm{d} 50$ to $\mathrm{d} 71$, followed by a $3 \mathrm{~d}$ withdrawal (COMBO).

${ }^{2} \mathrm{TRT}=$ Treatment

${ }^{3} \mathrm{DOA}=$ Day of aging.

${ }^{4}$ Purge loss calculated by ([initial loin weight-final loin weight]/initial loin weight) $\times 100$. Intital and final (d 21) loin weight collected on posterior portion of the strip loin that remained following removal of steaks from the anterior end for Warner-Bratzler shear force.

${ }^{5}$ Cook loss calculated by $([$ cooked weight - raw weight $] /$ raw weight $) \times 100$.

to have larger $(P=0.06) \mathrm{LM}$ area and reduced $(P=$ $0.09)$ 12th-rib s.c. fat thickness when compared to CON carcasses. Carcasses from COMBO cattle possessed larger LM area and less 12th-rib s.c. fat than CON carcasses $(P=0.01)$. When compared to each other, COMBO and IMP carcasses did not differ in $\mathrm{LM}$ area or BF thickness $(P>0.37)$. Percent $\mathrm{KPH}$ and strip loin weight did not differ $(P>0.11)$ by treatment and marbling score tended to be decreased $(P=0.09)$ by GP treatment.

\section{Purge and pH Measures}

$\mathrm{pH}$ was measured on $\mathrm{d} 3$ and 21 and displayed a treatment $\times$ DOA interaction $(P<0.01$; Table 3$)$. As loins were aged from d 3 to $\mathrm{d} 21$, the $C O N$ loins had a decrease $(P<0.01)$ in $\mathrm{pH}$, while IMP and COMBO loins did not experience a change in $\mathrm{pH}(P>0.24)$. This resulted in IMP and COMBO loins having a greater $\mathrm{pH}$ than $\mathrm{CON}$ loins at $\mathrm{d} 21$ of aging $(P<0.04)$, but their $\mathrm{pH}$ did not differ from each other $(P=0.43)$. Over all DOA, treatment did not affect $(P=0.54) \mathrm{pH}$; however, loin $\mathrm{pH}$ did drop $(P<0.01)$ from $\mathrm{d} 3$ to $\mathrm{d} 21$ of aging. It is also important to note, that the magni- 
Table 4. Warner-Bratzler shear force values from 3 locations within the Longissimus lumborum of heifers subjected to 3 exogenous growth-promoting programs ${ }^{1-8}$

\begin{tabular}{|c|c|c|c|c|c|c|c|c|c|c|}
\hline & \multicolumn{3}{|c|}{ Medial } & \multicolumn{3}{|c|}{ Medial/Lateral } & \multicolumn{3}{|c|}{ Lateral } & \multirow[b]{2}{*}{ SEM } \\
\hline & $\mathrm{CON}$ & IMP & COMBO & $\mathrm{CON}$ & IMP & COMBO & $\mathrm{CON}$ & IMP & COMBO & \\
\hline Day 3 & 4.40 & 5.51 & 6.02 & 4.22 & 5.38 & 6.27 & 4.06 & 4.86 & 5.92 & 0.36 \\
\hline Day 14 & 3.36 & 4.12 & 5.18 & 4.43 & 4.99 & 5.61 & 4.20 & 4.34 & 5.55 & 0.36 \\
\hline Day 21 & 3.36 & 3.89 & 4.76 & 4.45 & 4.66 & 4.64 & 4.27 & 4.19 & 4.39 & 0.36 \\
\hline Day 35 & 3.68 & 3.75 & 5.07 & 4.37 & 4.52 & 4.99 & 4.03 & 4.33 & 4.32 & 0.36 \\
\hline
\end{tabular}

${ }^{1}$ Crossbred feedlot heifers $(n=32)$ were subjected to 1 of 3 treatments: no implant or zilpaterol hydrochloride (CON); Component TE-200 implant (Elanco Animal Health, Greenfield, IN) on d 0 of study, no zilpaterol hydrochloride (IMP); and Component TE-200 implant on d 0 of study and zilpaterol hydrochloride (Merck Animal Health, Summit, NJ) at $8.3 \mathrm{mg} / \mathrm{kg}$ of ZH from d 50 to d 71, followed by a 3-d withdrawal (COMBO).

${ }^{2}$ Treatment $\times$ day of aging $\times$ location, $P=0.25$.

${ }^{3}$ Treatment $\times$ day of aging, $P<0.01$.

${ }^{4}$ Treatment $\times$ location, $P=0.04$.

${ }^{5}$ Day of aging $\times$ location, $P=0.04$.

${ }^{6}$ Treatment, $P<0.01$.

${ }^{7}$ Day of aging, $P<0.01$.

${ }^{8}$ Location, $P<0.01$.

tude of differences noted in this experiment are not large enough to impact meat quality.

After $21 \mathrm{~d}$ of aging, moisture retention was quantified on the remaining portion of the loin. Treatment affected d 21 purge loss with loins from IMP and COMBO loins having increased moisture loss when compared to $\mathrm{CON}$ loins $(P<0.02)$. When compared to each other, IMP and COMBO loins did not differ $(P=0.70)$ in the amount of moisture lost during aging. The moisture retention issues exhibited by GP supplemented cattle were not observed during cooking. There were no treatment $\times$ DOA interaction or treatment effects on cooking loss $(P>0.87)$, but DOA tended to impact $(P=0.06)$ cook loss. Steaks cooked on $\mathrm{d} 14$ lost more moisture than steaks cooked on $\mathrm{d} 3$ and $21(P<0.03)$. All other cook loss measures were not different from one another $(P>0.12)$.

\section{Warner-Bratzler Shear Force}

As expected, with increased DOA, WBSF values of all steaks decreased $(P<0.01)$ and became more tender (Table 4). There was no treatment $\times \mathrm{DOA} \times$ location interaction $(P>0.10)$ for WBSF values. The treatment $\times$ location interaction, treatment $\times \mathrm{DOA}$, and DOA $\times$ location interactions impacted objective tenderness $(P<$ $0.05)$. For the treatment $\times$ location interaction, the $\mathrm{CON}$ and IMP treatments were similar $(P=0.11)$ to one another, but were decreased $(P<0.01)$ when compared to the COMBO treatment at the MED location. At the M/L and LAT locations, the CON steaks did not differ $(P>0.17)$ from the IMP steaks, but were decreased $(P<0.02)$ when compared to the COMBO steaks. The IMP steaks did not differ $(P>0.11)$ from the COMBO steaks at the $\mathrm{M} / \mathrm{L}$ and LAT locations. When analyzing treatment $\times$ DOA interaction, at d 3 COMBO steaks had greater WBSF values than IMP and CON steaks $(P<0.01)$. Steaks from IMP treatment also had greater $(P=0.02)$ WBSF values when compared to CON steaks. After $14 \mathrm{~d}$ aging, the IMP and CON steaks did not differ $(P>0.21)$ from one another, but the WBSF for COMBO steaks continued to be greater than the CON and IMP treatments $(P<0.02)$. At d 21 of aging, WBSF values of steaks from all treatments did not differ $(P>0.13)$. Unlike the d 21 results, d 35 COMBO steaks were tougher $(P<0.04)$ than CON steaks; however, IMP steaks WBSF values did not differ from either of the other treatments $(P>0.13)$.

When considering the DOA $\times$ location interaction, the MED and $\mathrm{M} / \mathrm{L}$ locations possessed similar $(P=$ $0.91) \mathrm{WBSF}$ at $\mathrm{d} 3$ of aging. Also on this DOA, the WBSF values from the LAT location tended to be less when compared to the other 2 locations $(P<0.08)$. After $14 \mathrm{~d}$ of aging, MED cores had reduced WBSF values than cores from the $\mathrm{M} / \mathrm{L}$ and LAT locations $(P<0.02)$, but cores from these locations did not differ $(P=0.12)$. Following $21 \mathrm{~d}$ aging, WBSF values of MED cores continued to be less $(P<0.01)$ than $\mathrm{M} / \mathrm{L}$ cores, but there was no difference $(P=0.17)$ between MED and LAT cores. The $\mathrm{M} / \mathrm{L}$ and LAT continued to maintain similar $(P=0.13) \mathrm{WBSF}$ values on this DOA. After $35 \mathrm{~d}$ aging, the $\mathrm{M} / \mathrm{L}$ location had greater $(P<0.05) \mathrm{WBSF}$ values when compared to the other locations, which did not differ from one another $(P<0.78)$. Over all DOA, location of cores within the steak affected $(P<0.01)$ WBSF. The M/L had greater $(P<0.01)$ WBSF values when compared to the MED and LAT locations, but the MED and LAT locations were similar $(P>0.32)$ to each other. Treatment also impacted $(P<0.01)$ WBSF of steaks. Over the entire aging study, steaks from CON and IMP cattle had similar $(P=0.15)$ WBSF. When compared to COMBO steaks, the CON steaks had decreased $(P<$ 
Table 5. Myosin heavy chain (MHC) distribution and cross-sectional area from 3 locations within the Longissimus lumborum of heifers subjected to 3 exogenous growth-promoting programs ${ }^{1}$

\begin{tabular}{|c|c|c|c|c|c|c|c|c|c|c|}
\hline & \multicolumn{3}{|c|}{ Medial } & \multicolumn{3}{|c|}{ Medial/Lateral } & \multicolumn{3}{|c|}{ Lateral } & \multirow[b]{2}{*}{ SEM } \\
\hline & $\mathrm{CON}$ & IMP & COMBO & $\mathrm{CON}$ & IMP & COMBO & $\mathrm{CON}$ & IMP & COMBO & \\
\hline \multicolumn{11}{|l|}{$\overline{\text { MHC type } \mathrm{I}^{2}}$} \\
\hline Percentage $^{4}$ & 28.7 & 27.8 & 29.6 & 30.3 & 30.8 & 32.1 & 30.2 & 28.5 & 30.5 & 1.5 \\
\hline Cross-sectional area ${ }^{3,4}, \mu \mathrm{m}^{2}$ & 2,104 & 2,628 & 2,440 & 2,195 & 2,597 & 2,475 & 1,915 & 2,275 & 2,104 & 152 \\
\hline \multicolumn{11}{|l|}{ MHC type IIA ${ }^{2}$} \\
\hline Percentage $^{4}$ & 43.6 & 49.2 & 46.8 & 39.7 & 43.4 & 42.4 & 38.2 & 42.8 & 38.9 & 3.2 \\
\hline Cross-sectional area ${ }^{4,5}, \mu \mathrm{m}^{2}$ & 3,063 & 3,482 & 3,765 & 3,219 & 3,441 & 3,781 & 2,693 & 3,147 & 3,374 & 280 \\
\hline \multicolumn{11}{|l|}{ MHC type IIX ${ }^{2}$} \\
\hline Percentage $^{4}$ & 27.7 & 23.3 & 23.6 & 30.0 & 26.1 & 25.5 & 31.6 & 29.0 & 30.6 & 3.5 \\
\hline Cross-sectional area ${ }^{3}, \mu \mathrm{m}^{2}$ & 2,983 & 3,617 & 4,222 & 3,420 & 3,798 & 4,165 & 3,165 & 3,492 & 4,112 & 240 \\
\hline \multicolumn{11}{|c|}{$\begin{array}{l}{ }^{1} \text { Crossbred feedlot heifers }(n=32) \text { were subjected to } 1 \text { of } 3 \text { treatments: no implant or zilpaterol hydrochloride }(\mathrm{CON}) \text {; Component TE-200 implant } \\
\text { (Elanco Animal Health, Greenfield, IN) on d } 0 \text { of study, no zilpaterol hydrochloride (IMP); and Component TE-200 implant on d } 0 \text { of study and zilpaterol } \\
\text { hydrochloride (Merck Animal Health, Summit, NJ) at } 8.3 \mathrm{mg} / \mathrm{kg} \text { of ZH from d } 50 \text { to d 71, followed by a 3-d withdrawal (COMBO). }\end{array}$} \\
\hline \multicolumn{11}{|c|}{${ }^{2}$ There were no treatment $\times$ location interactions for MHC distribution or cross-sectional area $(P>0.70)$} \\
\hline \multicolumn{11}{|c|}{${ }^{3}$ Treatment, $P<0.03$} \\
\hline \multicolumn{11}{|l|}{${ }^{4}$ Location, $P<0.04$. } \\
\hline${ }^{5}$ Treatment, $P<0.06$. & & & & & & & & & & \\
\hline
\end{tabular}

0.01) WBSF values, while IMP steaks tended to have decreased $(P=0.06) \mathrm{WBSF}$ values.

\section{Muscle Fiber Morphometrics}

To explore biological factors influencing WBSF, immunohistochemical analysis was utilized to examine the effects of steak location and GP treatment on muscle fiber type and morphometrics (Table 5). Each of 3 myosin heavy chain isoforms were analyzed independently. There were no treatment $\times$ location interactions for muscle fiber type percentages and associated fiber CSA $(P>$ 0.70). Treatment did not affect the percentage of all 3 muscle fiber types $(P>0.49)$, but the types were affected by location $(P<0.01)$. The MED location had less $(P<$ $0.01)$ type I fibers than the $\mathrm{M} / \mathrm{L}$ location, but possessed $(P=0.19)$ the same percentage of type I fibers as the LAT location. The $\mathrm{M} / \mathrm{L}$ location tended to possess more $(P=$ 0.08) type I fibers than the LAT location. The MED location possessed more type IIA fibers than the other 2 steak locations $(P<0.01)$, which did not differ $(P=0.11)$ from each other. The MED location possessed less $(P<0.01)$ type IIX fibers than the M/L location, which possessed less $(P<0.01)$ IIX fibers than the LAT location.

Treatment affected the CSA of type I and IIX fibers $(P<0.02)$ and tended to affect $(P=0.06)$ the CSA of IIA fibers. Compared to CON fibers, IMP fibers were larger $(P<0.01)$, while COMBO fibers tended to be $\operatorname{larger}(P=$ $0.08)$. Type I fibers of IMP and COMBO muscles did not $\operatorname{differ}(P=0.30)$. Type IIA fibers from IMP and COMBO muscles also did not differ $(P=0.30)$ from one another, but COMBO IIA fibers were larger $(P=0.02)$ than CON fibers. Type IIA fibers of CON and IMP muscles did not differ $(P=0.18)$ in size. Type IIX fiber CSA from
COMBO heifers were larger than IIX fibers from both IMP and the CON heifers $(P<0.02)$. When compared to one another, IMP type IIX CSA was greater $(P=0.05)$ than that of CON fibers. Cross-sectional area data indicated that type I and IIA CSA was affected by steak location $(P<0.01)$, while there was no effect $(P=0.33)$ on type IIX fiber CSA. The LAT location had smaller type I and IIA fiber CSA when compared to the MED area $(P<$ $0.01)$. The LAT location possessed smaller $(P<0.01)$ type I fibers than the $\mathrm{M} / \mathrm{L}$ location, but type IIA CSA did not differ $(P<0.18)$ between these areas.

\section{Collagen Analysis}

There were no treatment $\times \mathrm{DOA} \times$ location, treatment $\times$ location, or DOA $\times$ location interactions for amounts of soluble collagen measured (Table $6 ; P>$ 0.42 ); however, there tended to be a treatment $\times$ DOA interaction $(P=0.06)$. Day of aging influenced amount of collagen, with collagen solubility differing $(P<0.01)$ between $\mathrm{d} 14$ and 21 and tending to differ $(P=0.10) \mathrm{d}$ 3 and 21. All other day comparisons were not different from one another $(P>0.13)$. Location within steak also impacted collagen solubility, with $\mathrm{M} / \mathrm{L}$ area possessing more soluble collagen than the MED and LAT areas $(P<$ $0.05)$, and the MED area having more $(P=0.02)$ soluble collagen that the LAT area. Day of aging, treatment, location, and their 2-way and 3-way interactions did not affect total or insoluble collagen $(P>0.11)$.

\section{Correlation Coefficients}

Pearson's correlation coefficients between WBSF and myofibrillar and collagen characteristics are dis- 
Table 6. Collagen characteristics from 3 locations within the Longissimus lumborum from heifers subjected to 3 exogenous growth-promoting programs ${ }^{1}$

\begin{tabular}{|c|c|c|c|c|c|c|c|c|c|c|}
\hline \multirow[b]{2}{*}{ Collagen } & \multicolumn{3}{|c|}{ Medial } & \multicolumn{3}{|c|}{ Medial/Lateral } & \multicolumn{3}{|c|}{ Lateral } & \multirow[b]{2}{*}{ SEM } \\
\hline & $\mathrm{CON}$ & IMP & COMBO & $\mathrm{CON}$ & IMP & COMBO & $\mathrm{CON}$ & IMP & COMBO & \\
\hline \multicolumn{11}{|c|}{ Soluble, ${ }^{2-5} \mathrm{mg} / \mathrm{g}$} \\
\hline Day 3 & 0.98 & 1.31 & 0.97 & 0.93 & 1.15 & 1.00 & 0.65 & 0.66 & 0.90 & 0.23 \\
\hline Day 14 & 0.78 & 0.81 & 0.56 & 0.70 & 1.53 & 1.08 & 0.66 & 0.63 & 0.62 & 0.23 \\
\hline Day 21 & 1.04 & 0.84 & 1.71 & 0.89 & 1.29 & 1.52 & 0.64 & 0.97 & 1.26 & 0.23 \\
\hline Day 35 & 0.63 & 1.13 & 1.02 & 1.40 & 1.22 & 0.90 & 0.78 & 0.83 & 0.89 & 0.23 \\
\hline \multicolumn{11}{|c|}{ Insoluble, ${ }^{6} \mathrm{mg} / \mathrm{g}$} \\
\hline Day 3 & 6.94 & 5.04 & 6.32 & 5.15 & 4.18 & 4.66 & 4.99 & 5.00 & 5.25 & 0.94 \\
\hline Day 14 & 6.75 & 4.08 & 5.77 & 6.16 & 4.53 & 5.73 & 5.39 & 5.97 & 5.32 & 0.94 \\
\hline Day 21 & 4.72 & 6.76 & 4.82 & 4.95 & 5.13 & 5.42 & 5.90 & 4.62 & 6.76 & 0.94 \\
\hline Day 35 & 5.31 & 4.41 & 7.25 & 5.33 & 5.07 & 5.12 & 5.37 & 5.44 & 5.92 & 0.94 \\
\hline \multicolumn{11}{|c|}{ Total, ${ }^{6} \mathrm{mg} / \mathrm{g}$} \\
\hline Day 3 & 7.92 & 6.35 & 7.33 & 6.08 & 5.33 & 5.71 & 5.64 & 5.66 & 6.17 & 1.03 \\
\hline Day 14 & 7.54 & 4.89 & 6.33 & 6.85 & 6.06 & 6.78 & 6.05 & 6.60 & 5.94 & 1.03 \\
\hline Day 21 & 5.74 & 7.60 & 6.53 & 5.84 & 6.42 & 6.94 & 6.54 & 5.59 & 8.02 & 1.03 \\
\hline Day 35 & 5.94 & 5.54 & 8.27 & 6.73 & 6.29 & 6.03 & 6.15 & 6.27 & 6.81 & 1.03 \\
\hline
\end{tabular}

${ }^{1}$ Crossbred feedlot heifers $(n=32)$ were subjected to 1 of 3 treatments: no implant or zilpaterol hydrochloride (CON); Component TE-200 implant (Elanco Animal Health, Greenfield, IN) on d 0 of study, no zilpaterol hydrochloride (IMP); Component TE-200 implant on d 0 of study and zilpaterol hydrochloride (Merck Animal Health, Summit, NJ) at $8.3 \mathrm{mg} / \mathrm{kg}$ of ZH from d 50 to d 71, followed by a 3-d withdrawal (COMBO).

${ }^{2}$ There were no treatment $\times$ day of aging $\times$ location, treatment $\times$ location, day of aging $\times$ location, or treatment main effect $(P>0.21)$.

${ }^{3}$ Treatment $\times$ day of aging, $P=0.06$.

${ }^{4}$ Day of aging, $P<0.03$

${ }^{5}$ Location, $P<0.01$.

${ }^{6}$ Treatment, day of aging, location, and their 2- and 3-way interactions were not significant $(P>0.31)$.

played in Table 7. On d 3 of aging, the CSA of all fiber types were positively correlated with $\operatorname{WBSF}(P<$ $0.01)$, while all collagen characteristics were not correlated $(P>0.10)$. After $14 \mathrm{~d}$ of aging, CSA of all fiber types were still correlated $(P<0.05)$ to WBSF, but correlations were not as strong. All collagen measures were not correlated to WBSF $(P>0.10)$. At d 21 of aging, WBSF was not correlated to type I and IIA fiber CSA and soluble collagen content $(P>0.14)$. Type IIX fiber CSA was still correlated $(P=0.03)$ to WBSF at $\mathrm{d} 21$ of aging and insoluble and total collagen content also became correlated $(P<0.01)$. These trends were maintained through d 35 of aging $(P<0.05)$, but the correlations were not as strong as $\mathrm{d} 21$.

\section{DISCUSSION}

\section{Growth-Promoting Technologies Effects}

Addition of GP improves feedlot performance and overall amount of lean muscle tissue (Schmidt and Olson, 2007). Currently beef producers utilize several GP including, B-AA and anabolic implants. Two B-AA options are approved for use in beef cattle while the market currently possesses a multitude of anabolic implant options. In the current study, Component TE-200 or a combination of the implant and $\mathrm{ZH}$ were supplemented to finishing heifers. Over the 75-d feeding period, use of GP technologies did not improve feedlot performance measures, which is in contrast to the plethora of literature that documents drastic improvements in these measures. When examining studies that utilize implant strategies that consist of a similar hormone dosage as the current study (200 $\mathrm{mg}$ trenbolone acetate $/ 20 \mathrm{mg}$ estradiol), heifer ADG and $\mathrm{G}: \mathrm{F}$ can be increased by up to $50 \%$ and $31 \%$, respectively (Herschler et al., 1995; Popp et al., 1997; Guiroy et al., 2002). In agreement with the current study, Garber et al. (1990) found that implanting heifers with Synovex-H did not affect G:F; however, ADG was improved by the implant. The addition of $\mathrm{ZH}$ to feedlot diets provides equally impressive results by increasing ADG and G:F by up to $18 \%$ and $25 \%$, respectively (Montgomery et al., 2009; Rathmann et al., 2012). In the current study, combining the implant regimen with $\mathrm{ZH}$ did not improve feedlot performance of the heifers when compared to controls; however, the magnitude of increase in ADG and G:F were similar to improvements reported in literature $(22 \%$ and $18 \%$, respectively). Therefore, the lack of significance could be due to small animal numbers utilized in the study.

While GP regimens did not provide improvements in feedlot performance, advantages were demonstrated when examining carcass characteristics. In the current 
Table 7. Pearson's correlation coefficients between Warner-Bratzler shear force and fiber cross-sectional area, soluble collagen, insoluble collagen, and total collagen for steaks aged $3,14,21$, and $35 \mathrm{~d}$ postmortem from heifers subjected to 3 exogenous growthpromoting programs ${ }^{1}$

\begin{tabular}{|c|c|c|c|c|}
\hline \multirow[b]{2}{*}{ Item } & \multicolumn{4}{|c|}{ Warner-Bratzler shear force, $\mathrm{kg}$} \\
\hline & Day 3 & Day 14 & Day 21 & Day 35 \\
\hline \multicolumn{5}{|l|}{ Cross-sectional area, $\mu \mathrm{m}^{2}$} \\
\hline Type I & $0.51^{* *}$ & $0.45^{* *}$ & 0.26 & 0.19 \\
\hline Type IIA & $0.51 * *$ & $0.45^{*}$ & 0.27 & 0.25 \\
\hline Type IIX & $0.64 * *$ & $0.57 * *$ & $0.37 *$ & $0.37 *$ \\
\hline Soluble collagen, $\mathrm{mg} / \mathrm{g}$ & -0.22 & 0.11 & 0.34 & 0.05 \\
\hline Insoluble collagen, mg/g & -0.22 & 0.14 & $0.49 * *$ & $0.23 *$ \\
\hline Total collagen, mg/g & -0.26 & 0.15 & $0.54 * *$ & $0.30 *$ \\
\hline \multicolumn{5}{|c|}{$\begin{array}{l}{ }^{1} \text { Crossbred feedlot heifers }(n=32) \text { were subjected to } 1 \text { of } 3 \text { treatments: con- } \\
\text { trol, no implant or zilpaterol hydrochloride; implant only, Component TE-200 } \\
\text { implant (Elanco Animal Health, Greenfield, IN) on d } 0 \text { of study, no zilpaterol } \\
\text { hydrochloride; and combination, Component TE-200 implant on d } 0 \text { of study } \\
\text { and zilpaterol hydrochloride (Merck Animal Health, Summit, NJ) at } 8.3 \mathrm{mg} / \\
\mathrm{kg} \text { of ZH from d } 50 \text { to d 71, followed by a 3-d withdrawal. }\end{array}$} \\
\hline
\end{tabular}

study, the IMP treatment HCW and LM area tended to increase by $2 \%$ and $14 \%$, and increased yield grade by $28 \%$ when compared to CON carcasses, respectively. Garber et al. (1990) reported that implanting heifers did not increase HCW or yield grade, but did report a $6 \%$ increase in LM area. Other studies indicate that anabolic implants can increase both HCW and LM area modestly by $8 \%$ (Herschler et al., 1995; Popp et al., 1997). When $\mathrm{ZH}$ was added to the GP program and compared to the CON carcasses, HCW, yield grade, and LM area were increased by $5 \%, 33 \%$, and $18 \%$, respectively. The increase in HCW is comparable to other studies (Montgomery et al., 2009; Robles-Estrada et al., 2009; Rathmann et al., 2012); however, the increase in LM area and yield grade are much greater than these studies, which may be due to the combination of GP utilized in the COMBO treatment. Montgomery et al. (2009) found that heifers supplemented ZH without being administered anabolic implants had only a $9 \%$ increase in LM area and yield grade when compared to heifers not subjected to GP technologies. Both Robles-Estrada et al. (2009) and Rathmann et al. (2012) employed an anabolic implant in their control treatment and found that $\mathrm{ZH}$ can increase LM area and yield grade by only $6 \%$ and $9 \%$, respectively. This is similar to the current study, but the difference between the COMBO and IMP treatments were not significant.

Beta-adrenergic agonists are commonly referred to as repartitioning agents due to their ability to redirect nutrients from adipose to muscle growth. Carcasses from $\mathrm{ZH}$ heifers had 35\% less BF, but there was no effect on marbling score. The reduction in $\mathrm{BF}$ was much greater than the $5 \%$ reduction reported by Rathmann et al. (2009), but these authors also found no effect on marbling. In contrast, Montgomery et al. (2009) reported that BF thickness was unaffected by $\mathrm{ZH}$, but marbling score was reduced instead. Similar to the $\mathrm{ZH}$ literature, the effect of implants varies from study to study. In their review of the literature, Duckett and Pratt (2014) stated that anabolic implants do not or minimally influence 12 th rib BF thickness. Perry et al. (1991), Gerken et al. (1995), and Roeber et al. (2000) reported that various anabolic implants do not influence BF thickness. In the current study, BF thickness tended to be reduced by $25 \%$ in the IMP carcasses. Scheffler et al. (2003) indicated there may be a time of administration dependent influence on marbling score, with the administration of 1 implant late in finishing having the largest detrimental effect. The current study's results contradicts this finding by there being no effect on marbling with a single implant administration.

In the current study, WBSF values were greater for all treatment groups when compared to the majority of the literature. It is hypothesized this is due to all steaks being subjected to cooking without freezing, which commonly occurs during WBSF analysis (Shanks et al., 2002). In their review of the literature, Garmyn and Miller (2014) concluded that use of implants and $\mathrm{ZH}$ during finishing increases WBSF; however, retail studies would indicate these technologies elicit no adverse effects on objective or subjective tenderness measures. In the current study, the IMP treatment produced steaks that were tougher than CON steaks at $\mathrm{d} 3$ postmortem. By d 14 postmortem, IMP WBSF values were similar to CON steaks, which would indicate aging ameliorates adverse effects of implants on tenderness. This is in agreement with Schneider et al. (2007), who reported that steaks from heifers implanted with trenbolone acetate/estradiol required at least 14 to $28 \mathrm{~d}$ of aging to achieve WBSF values that would be predicted to achieve satisfactory consumer acceptance levels. Platter et al. (2003) found that implanted heifers maintained greater WBSF values through $21 \mathrm{~d}$ of aging. In agreement, Kerth et al. (2003) and Boles et al. (2009) also found that implanting heifers did not affect WBSF values at up to $21 \mathrm{~d}$ of aging.

While previous data indicated negative effects of implants on objective meat tenderness can be removed by postmortem aging, the impact of $\mathrm{ZH}$ on meat tenderness is substantial. Scramlin et al. (2010) reported that $21 \mathrm{~d}$ of postmortem aging did not alleviate the negative effects $\mathrm{ZH}$ elicits on cooked meat tenderness. Leheska et al. (2009) also found that heifers supplemented the same dosage of $\mathrm{ZH}$ produced steaks that were $24 \%$ greater in WBSF values after 28 DOA. Other studies also indicate that aging up to $35 \mathrm{~d}$ postmortem will not alleviate the negative impacts of $\mathrm{ZH}$ on objective tenderness (Brooks et al., 2009; Garmyn et al., 2011; Rathmann et al., 2012). In the current study, steaks from the COMBO treatment 
had greater WBSF values through 14 DOA, where they were $40 \%$ and $24 \%$ greater than CON and IMP steaks, respectively. At $\mathrm{d} 21$ of aging and due to a large reduction in shear force from d 14, COMBO steak WBSF were similar to the other 2 treatments. At $\mathrm{d} 35$ of aging and due to a slight elevation in the COMBO WBSF values, COMBO steaks were $20 \%$ tougher than CON steaks, which would agree with the previous literature that extended aging does not alleviate the negative effects of $\mathrm{ZH}$ on tenderness. Also of importance to note, the USDA has set a threshold for a guaranteed tender steak at a WBSF value of $4.4 \mathrm{~kg}$ (ASTM, 2011). For the current study, steaks from CON heifers began below this threshold, while it took IMP steaks $21 \mathrm{~d}$ to reach this value, and COMBO steaks never broke this threshold.

Myofibrillar and connective tissues are the 2determinants of shear force values (Møller, 1981). Myofibrillar proteins consist of contractile and cytoskeletal proteins that are responsible for muscle contraction and structure, respectively (Aberle et al., 2003). In beef cattle, postnatal muscle hypertrophy only occurs through hypertrophy of the existing fibers formed during fetal development (Strickland, 1978). In the current study, administering an anabolic implant increased CSA of type I and IIX fibers by $20 \%$ and $14 \%$, respectively, when compared to $\mathrm{CON}$. The literature indicates that all fiber types can be affected by implants. Fritsche et al. (2000) observed increased CSA for all fiber types for steers implanted with $120 \mathrm{mg}$ trenbolone acetate and 28 mg estradiol. Gonzalez et al. (2007) reported increases in type I fiber CSA of cull cows administered an anabolic implant with and without ractopamine- $\mathrm{HCl}$.

When $\mathrm{ZH}$ was combined with the anabolic implant and compared to CON in the current study, the CSA of all 3 fiber types were greater, with type IIX increasing the greatest (30\%). Kellermeier et al. (2009) conducted a similar study in steers and reported that average muscle fiber diameter increased by $3 \%$ and $6 \%$ when anabolic implants and $\mathrm{ZH}$ were utilized, respectively. While Rathmann et al. (2009) and Baxa et al. (2010) did not directly measure fiber CSA or diameter, they did indicate increases in the mRNA expression of type IIX muscle fibers demonstrated $\mathrm{ZH}$ increased protein synthesis of this isoform. Other B-AA have also increased muscle fiber CSA. Miller et al. (1988) and Vestergaard et al. (1994) found the diameter of type II fibers were increased by the administration of clenbuterol. Phelps et al. (2014a) reported steers supplemented with ractopamine- $\mathrm{HCl}$ tended to have increased CSA of type IIA fibers.

The importance of muscle fiber CSA on meat tenderness is demonstrated by the correlation analysis conducted in the current study. Previous research by Crouse et al. (1991) indicated that average muscle fiber size was correlated to shear force at d 1 and 3 of aging, but not correlated on d 6 or 14. Through d 14 of aging in the current study, CSA of all fiber types were correlated to WBSF; however, for the remaining 2 aging periods, the CSA of the smaller muscle fiber types (type I and IIA) were not correlated to objective tenderness. Additionally, type IIX fibers were strongly influenced by both GP. These findings would indicate the size of muscle fibers have a greater influence on tenderness during early postmortem aging, but ultimately, size of IIX fibers are the main contributors to meat tenderness when meat is aged past $14 \mathrm{~d}$. Additionally, the extent that GP influence the increase in muscle fiber CSA may ultimately impact cooked meat tenderness.

Connective tissue or collagen is the second major tissue structure than can affect cooked meat tenderness. Correlation analysis indicated as type I and IIA muscle fiber CSA became less correlated to WBSF, the total and insoluble collagen content correlation increased. Thus, this would indicate that these 2 collagen measures become more important to tenderness as meat is aged longer. The main components of anabolic implants, TBA and estradiol, both increase protein synthesis and decrease protein degradation (Kamanga-Sollo et al., 2010; 2011). While not conclusively proven, B-AA stimulate muscle hypertrophy by an increase in protein synthesis, a reduction in protein degradation, or a combination of both (for review, see Mersmann, 1998). Numerous studies have reported calpastatin activity is elevated by B-AA, which reduces protein degradation (Kretchmar et al., 1990; Koohmaraie et al., 1991; Strydom et al., 2009). Therefore, it is not unreasonable to hypothesize that implants and B-AA may also slow the rate of collagen degradation, which could encourage the formation of collagen crosslinks and reduce the solubility of collagen (McCormick, 1999). Trained panelists have detected an increase in the amount of detectable connective tissue when GP are utilized (Phelps et al., 2014a). In the current study, treatment did not affect any collagen measures. Calkins et al. (1986) and Faucitano et al. (2008) reported no implant effect on total or soluble collagen content and percent soluble collagen. Huck et al. (1991) also found collagen solubility was unaffected when more aggressive implants were administered to steers. In contrast, Strydom et al. (2009) found when ZH was added to an anabolic implant regimen, total collagen content was reduced, while soluble and insoluble collagen percentage was unaffected. Kellermeier et al. (2009) also reported steers not administered GP had more total collagen than steers administered a combination of anabolic implants and $\mathrm{ZH}$. The authors hypothesized the increase in muscle CSA in the GP treatments may have diluted the amount of total collagen present in the muscle. While the literature indicates that GP either elicit no effect or a positive 
effect on crude collagen measures, Roy et al. (2015) reported GP influenced collagen cross-link content in a muscle and age dependent manner. Therefore, measuring actual collagen cross-links may provide more valuable information about the impact GP have on tenderness.

\section{Effects of Within Steak Location}

Phelps et al. (2014b) indicated the locations examined in the current study differ in muscle fiber type composition, with the MED location possessing less type I and more type IIX fibers than the other locations. Therefore, a secondary objective of the study was to determine if the GP affected the locations of the LL muscle differently. The lack of treatment $\times$ location interactions for all dependent variables of interest indicates that the GP treatments affected all locations within the LL equally; however, there were still some important location effects to note. There was a location $\times$ DOA interaction for WBSF. On $\mathrm{d} 3$ of aging, WBSF value of the LAT portion of the loin was $0.4 \mathrm{~kg}$ less than the MED and M/L locations. As aging advanced to $\mathrm{d} 14$, the WBSF of the MED portion of the loin dropped quite extensively causing it to be reduced compared to the M/L and LAT locations by 0.79 $\mathrm{kg}$ and $0.48 \mathrm{~kg}$, respectively. By d 35 of aging, the WBSF of the MED and LAT locations did not differ, while M/L WBSF was different from the 2 locations by a maximum of $0.46 \mathrm{~kg}$. This pattern of WBSF decline indicated that each area ages differently. Numerous studies have examined the effect of location within the cross-section of the LL on WBSF and the results are quite divergent amongst the studies. In agreement with the current study, Janz et al. (2006) reported the lateral location sheared with less force than the medial location when steaks were aged 24 h. Hedrick et al. (1968) reported the medial portion of the LL was more tender than the central and lateral portions of steaks aged $10 \mathrm{~d}$. Berry (1993) found the lateral portion of the LL possessed greater shear values than the middle and medial portions when steaks were aged $15 \mathrm{~d}$, which agrees with Kerth et al. (2002), who found the same pattern after aging steaks 7 and 14-d postmortem. Derington et al. (2011) aged steaks of various quality grades $21 \mathrm{~d}$ and found lateral and middle shear values were greater than medial values across the entire strip-loin. Crouse et al. (1989) indicated shear force differences between the locations may be dependent on the overall tenderness classification of the steaks. The authors reported shear force was reduced when cores were taken medial to lateral in tender steaks, but the opposite was found when steaks were tough.

Most of the studies discussed above took their measurements at different time points, while the current study examined the location effects over time. The different trajectories of the locations' aging patterns would indicate there are inherent differences in the biology of the locations. In addition to having the smallest WBSF values at $\mathrm{d} 3$, the LAT location also possessed the smallest type I and IIA fibers. Because correlation analysis indicates these fibers influenced shear at this time point, this could partially explain the WBSF differences seen at $\mathrm{d} 3$. As the meat is aged postmortem, the data in the current study does not adequately explain the differences in the aging patterns between the locations. There are no other clear muscle fiber type patterns that could aid in explaining differences and soluble collagen content of the locations are opposite of what one would expect for the WBSF/soluble collagen relationship; the LAT location contained the least soluble collagen, while the M/L location possessed the most. Therefore, other mechanisms, such as the calpain proteolytic system, may be responsible for the divergent aging patterns of the 3 locations.

\section{LITERATURE CITED}

Aberle, E. D., J. C. Forrest, D. E. Gerrard, and E. W. Mills. 2003. Principles of Meat Science. 4th ed. Kendall/Hunt Publishing Co., Dubuque, IA.

AMSA. 1995. Research guidelines for cookery, sensory evaluation and instrumental tenderness measurements of fresh meat. Natl. Livest. Meat Board, Chicago, IL.

AOAC. 2005. Official methods of analysis. 18th ed. Assoc. Off. Anal. Chem., Gaithersburg, MD.

ASTM 2011. F2925-11. Standard specification for tenderness marketing claims associated with meat cuts derived from beef. ATSM Int., West Conshohocken, PA. http://www.astm.org.

Baxa, T. J., J. P. Hutcheson, M. F. Miller, J. C. Brooks, W. T. Nichols, M. N. Streeter, D. A. Yates, and B. J. Johnson. 2010. Additive effects of a steroidal implant and zilpaterol hydrochloride on feedlot performance, carcass characteristics, and skeletal muscle messenger ribonucleic acid abundance in finishing steers. J. Anim. Sci. 88:330-337.

Bergman, I., and R. Loxley. 1963. Two improved and simpliðed methods for the spectrophotometric determination of hydroxyproline. Anal. Chem. 35:1961-1965 10.1021/ ac60205a053

Berry, B. W. 1993. Tenderness of beef loin steaks as influenced by marbling level, removal of subcutaneous fat, and cooking method. J. Anim. Sci. 71:2412-2419.

Boles, J. A., D. L. Boss, K. I. Neary, K. C. Davis, and M. W. Tess. 2009. Growth implants reduced tenderness of steaks from steers and heifers with different genetic potentials for growth and marbling. J. Anim. Sci. 87:269-274.

Brooks, J. C., H. C. Claus, M. E. Dikeman, J. Shook, G. G. Hilton, T. E. Lawrence, J. M. Mehaffey, B. J. Johnson, D. M. Allen, M. N. Streeter, W. T. Nichols, J. P. Hutcheson, D. A. Yates, and M. F. Miller. 2009. Effects of zilpaterol hydrochloride feeding duration and postmortem aging on Warner-Bratzler shear force of three muscles from beef steers and heifers. J. Anim. Sci. 87:3764-3769.

Calkins, C. R., D. C. Clanton, T. J. Berg, and J. E. Kinder. 1986. Growth, carcass and palatability traits of intact males and steers implanted with zeranol or estradiol early and throughout life. 1986. J. Anim. Sci. 62:625-631.

Cross, H. R., Z. L. Carpenter, and G. C. Smith. 1973. Effects of intramuscular collagen and elastin on bovine muscle tenderness. J. Food Sci. 38:998-1003. 
Crouse, J. D., L. K. Theer, and S. C. Seideman. 1989. The measurement of shear force by core location in longissimus dorsi beef steaks from four tenderness groups. J. Food Qual. 11:341-347.

Crouse, J. D., M. Koohmaraie, and S. D. Seideman. 1991. The relationship of muscle fibre size to tenderness of beef. Meat Sci. 30:295-302.

Derington, A.J., J.C. Brooks, A.J. Garmyn, L.D. Thompson, D.B. Wester, and M.F. Miller. 2011. Relationships of slice shear force and Warner-Bratzler shear force of beef strip loin steaks as related to the tenderness gradient of the strip loin. Meat Sci. 88:203-208 10.1016/j.meatsci.2010.12.030. doi:10.1016/j. meatsci.2010.12.030.

Duckett, S.K., and S.L. Pratt. 2014. Meat Science and Muscle Biology Symposium: anabolic implants and meat quality. J. Anim. Sci. 92:3-9 10.2527/jas.2013-7088. doi:10.2527/jas.2013-7088.

Faucitano, L., P.Y. Chouinard, J. Fortin, I.B. Mandell, C. Lafrenière, C.L. Girard, and R. Berthiaume. 2008. Comparison of alternative beef production systems based on forage finishing or grain-forage diets with or without growth promotants: 2 . Meat quality, fatty acid composition, and overall palatability. J. Anim. Sci. 86:16781689 10.2527/jas.2007-0756. doi:10.2527/jas.2007-0756.

Fritsche, S., M.D. Solomon, E.W. Paroczay, and T.S. Rumsey. 2000. Effects of growth-promoting implants on morphology of Longissimus and Semitendinosus muscles in finishing steers. Meat Sci. 56:229-237 10.1016/S0309-1740(00)00047-4. doi:10.1016/S0309-1740(00)00047-4.

Garber, M. J., R. A. Roeder, J. J. Combs, L. Eldridge, J. C. Miller, D. D. Hinman, and J. J. Ney. 1990. Efficacy of vaginal spaying and anabolic implants on growth and carcass characteristics in beef heifers. J. Anim. Sci. 68:1469-1475. doi:/1990.6851469x.

Garmyn, A.J., S.M. Knobel, K.S. Spivey, L.F. Hightower, J.C. Brooks, B.J. Johnson, S.L. Parr, R.J. Rathmann, J.D. Starkey, D.A. Yates, J.M. Hodgen, J.P. Hutcheson, and M.F. Miller. 2011. WarnerBratzler and slice shear force measurements of 3 beef muscles in response to various aging periods after trenbolone acetate and estradiol implants and zilpaterol hydrochloride supplementation of finishing beef steers. J. Anim. Sci. 89:3783-3791 10.2527/ jas.2011-4134. doi:10.2527/jas.2011-4134.

Garmyn, A.J., and M.F. Miller. 2014. MEAT SCIENCE AND MUSCLE BIOLOGY SYMPOSIUM-Implant and beta agonist impacts on beef palatability. J. Anim. Sci. 92:10-20 10.2527/jas.2013-7097. doi:10.2527/jas.2013-7097.

Gerken, C. L. J. D. Tatum, J. B. Morgan, and G. C. Smith. 1995. Use of genetically identical (clone) steers to determine the effects of estrogenic and androgenic implants on beef quality and palatability characteristics. J. Anim. Sci. 73:3317-3324. doi:/1995.73113317x.

Gonzalez, J.M., J.N. Carter, D.D. Johnson, S.E. Ouellette, and S.E. Johnson. 2007. Effect of ractopamine-hydrochloride and trenbolone acetate on longissimus muscle fiber area, diameter, and satellite cell numbers in cull beef cows. J. Anim. Sci. 85:18931901 10.2527/jas.2006-624. doi:10.2527/jas.2006-624.

Guiroy, P. J., L. O. Tedeschi, D. G. Fox, and J. P. Hutcheson. 2002. The effects of implant strategy on finished body weight of beef cattle. J. Anim. Sci. 80:1791-1800. doi:/2002.8071791x.

Hedrick, H.B., W.C. Stringer, R.J. Epley, M.A. Alexander, and G.F. Krause. 1968. Comparison of factors affecting WarnerBratzler shear values of beef steaks. J. Anim. Sci. 27:628-631 10.2134/jas1968.273628x..

Herschler, R. C., A. W. Olmsted, A. J. Edwards, R. L. Hale, T. Montgomery, R. L. Preston, S. J. Bartle, and J. J. Sheldon. 1995. Production responses to various doses and ratios of estradiol benzoate and trenbolone acetate implants in steers and heifers. J. Anim. Sci. 73:2873-2881. doi:/1995.73102873x.

Hill, F. 1966. The solubility of intramuscular collagen in meat animals of various ages. J. Food Sci. 31:161-166 10.1111/j.1365- 2621.1996.tb00472.x. doi:10.1111/j.1365-2621.1966.tb00472.x. Howard, B., J. Gonzalez, W. Keller, J. Drouillard, K. Phelps, S. Ebarb, and K. Maddock-Carlin. 2015. Effects of implanting strategy and Zilpaterol Hydrochloride on the calpain proteolytic system in sectioned beef steaks aged for two time periods. 68th Recip. Meat Conf. Proc., Lincoln, NE.

Huck, G.L., R.T. Brandt, Jr., M.E. Dikeman, D.D. Simms, and G.L. Kuhl. 1991. Timing of trenbolone acetate implants on performance, carcass characteristics, and beef quality of finishing steer calves. Kansas State University Cattlemen's Day report. p. 90-92.

Janz, J. A., J. L. Aalhus, M. E. Dugan, and M. A. Price. 2006. A mapping method for the description of Warner-Bratzler shear force gradients in beef Longissimus thoracis et lumborum and Semitendinosus. 2006. Meat Sci. 72:79-90. doi:10.1016/j. meatsci.2005.06.009.

Kamanga-Sollo, E., M.E. White, M.R. Hathaway, W.J. Weber, and W.R. Dayton. 2010. Effect of estradiol-17beta on protein synthesis and degradation rates in fused bovine satellite cell cultures. Domest. Anim. Endocrinol. 39:54-62 10.1016/j.domaniend.2010.02.002. doi:10.1016/j.domaniend.2010.02.002.

Kamanga-Sollo, E., M.E. White, M.R. Hathaway, W.J. Weber, and W.R. Dayton. 2011. Effect of trenbolone acetate on protein synthesis and degradation rates in fused bovine satellite cell cultures. Domest. Anim. Endocrinol. 40:60-66 10.1016/j. domaniend.2010.08.007. doi:10.1016/j.domaniend.2010.08.007.

Kellermeier, J.D., A.W. Titlor, J.C. Brooks, M.L. Galyean, D.A. Yates, J.P. Hutcheson, W.T. Nichols, M.N. Streeter, B.J. Johnson, and M.F. Miller. 2009. Effects of zilpaterol hydrochloride with or without an estrogen-trenbolone acetate terminal implant on carcass traits, retail cutout, tenderness, and muscle fiber diameter in finishing steers. J. Anim. Sci. 87:3702-3711 10.2527/ jas.2009-1823. doi:10.2527/jas.2009-1823.

Kerth, C. R., J. L. Montgomery, J. L. Lansdell, C.B. Ramsey, and M.F. Miller. 2002. Shear gradient in longissimus steaks. J. Anim. Sci. 80:2390-2395. doi:/2002.8092390x.

Kerth, C. R., J. L. Montgomery, K. J. Morrow, M. L. Galyean, and M. F. Miller. 2003. Protein turnover and sensory traits of longissimus muscle from implanted and nonimplanted heifers. J. Anim. Sci. 81:1728-1735. doi:/2003.8171728x.

Koohmaraie, M., S. D. Shackelford, N. E. Muggli-Cockett, and R. T. Stone. 1991. Effect of the beta-adrenergic agonist L644,969 on muscle growth, endogenous proteinase activities, and postmortem proteolysis in wether lambs. J. Anim. Sci. 69:4823-4835. doi:/1991.69124823x.

Kretchmar, D. H., M. R. Hathaway, R. J. Epley, and W. R. Dayton. 1990. Alterations in postmortem degradation of myofibrillar proteins in muscle of lambs fed a beta-adrenergic agonist. J. Anim. Sci. 68:1760-1772. doi:/1990.6861760x.

Lean, I.J., J.M. Thompson, and F.R. Dunshea. 2014. A metaanalysis of zilpaterol and ractopamine effects on feedlot performance, carcass traits and shear strength of meat in cattle. PLoS ONE 9(12):e115904 10.1371/journal.pone.0115904. doi:10.1371/journal.pone.0115904.

Leheska, J.M., J.L. Montgomery, C.R. Krehbiel, D.A. Yates, J.P. Hutcheson, W.T. Nichols, M. Streeter, J.R. Blanton, Jr., and M.F. Miller. 2009. Dietary zilpaterol hydrochloride. II. Carcass composition and meat palatability of beef cattle. J. Anim. Sci. 87:1384 1393 10.2527/jas.2008-1168. doi:10.2527/jas.2008-1168.

McCormick, R.J. 1999. Extracellular modifications to muscle collagen: implications for meat quality. Poult. Sci. 78:785-791 10.1093/ps/78.5.785. doi:10.1093/ps/78.5.785.

Mersmann, H. J. 1998. Overview of the effects of beta-adrenergic receptor agonists on animal growth including mechanisms of action. J. Anim. Sci. 76:160-172. doi:/1998.761160x.

Miller, M.F., D.K. Garcia, M.E. Coleman, P.A. Ekeren, D.K. Lunt, K.A. Wagner, M. Procknor, T.H. Welsh, and S.B. Smith. 
1988. Adipose tissue, longissimus muscle and anterior pituitary growth and function in clenbuterol-fed heifers. J. Anim. Sci. 66:12-20 10.2134/jas1988.66112x.

Møller, A.J. 1981. Analysis of Warner-Bratzler shear pattern with regard to myofibrillar and connective tissue components of tenderness. Meat Sci. 5:247-260 10.1016/03091740(81)90015-2. doi:10.1016/0309-1740(81)90015-2.

Montgomery, J.L., C.R. Krehbiel, J.J. Cranston, D.A. Yates, J.P. Hutcheson, W.T. Nichols, M.N. Streeter, D.T. Bechtol, E. Johnson, T. TerHune, and T.H. Montgomery. 2009. Dietary zilpaterol hydrochlorie I. Feedlot performance and carcass traits of steers and heifers. J. Anim. Sci. 87:1374-1383 10.2527/jas.2008-1162. doi:10.2527/jas.2008-1162.

Moreno-Sanchez, N., C. Diaz, M. J. Carabano, J. Rueda, and J. L. Rivero. 2008. A comprehensive characterization of the fibre composition and properties of a limb (Flexor digitorum superficialis, membri thoracic) and a trunk (Psoas major) muscle in cattle. BMC Cell Biol. 9:67.

Perry, T. C., D. G. Fox, and D. H. Beermann. 1991. Effect of an implant of trenbolone acetate and estradiol on growth, feed efficiency, and carcass composition of Holstein and beef steers. J. Anim. Sci. 69:4696-4702. doi:/1991.69124696x.

Phelps, K.J., J.S. Drouillard, J.S. Jennings, B.E. Depenbusch, C.L. Van Bibber-Krueger, K.A. Miller, M.A. Vaughn, D.D. Burnett, S.M. Ebarb, T.A. Houser, S.E. Johnson, and J.M. Gonzalez. 2014a. Effects of the Programmed Nutrition Beef Program on meat quality characteristics. J. Anim. Sci. 92:1780-1791 10.2527/jas.2013-7231. doi:10.2527/jas.2013-7231.

Phelps, K.J., M. A. Vaughn, S. M. Ebarb, D. D. Burnett, J.S. Drouillard, and J. M. Gonzalez. 2014b. Muscle fiber and color characteristics of different locations within beef Longissimus lumborum steaks. J. Anim. Sci. 92(E-Suppl. 2):214. (Abstr.).

Platter, W. J., J. D. Tatum, K. E. Belk, J. A. Scanga, and G.C. Smith. 2003. Effects of repetitive use of hormonal implants on beef carcass quality, tenderness, and consumer ratings of beef palatability. J. Anim. Sci. 81:984-996. doi:/2003.814984x.

Popp, J.D., T.A. McAllister, W.J. Burgevitz, R.A. Kemp, J.P. Kastelic, and K.J. Cheng. 1997. Effect of trenbolene acetate/ estradiol implants and estrus suppression on growth performance and carcass charateristics of beef heifers. Can. J. Anim. Sci. 77(2):325-328 10.4141/A97-001. doi:10.4141/A97-001.

Rathmann, R. J., J. M. Mehaffey, T. J. Baxa, W. T. Nichols, D. A. Yates, J. P. Hutcheson, J. C. Brooks, B. J. Johnson, and M. F. Miller. 2009. Effects of duration of zilpaterol hydrochloride and days on the finishing diet on carcass cutability, composition, tenderness, and skeletal muscle gene expression in feedlot steers. 87:3686-3701. doi:10.2527/jas.2009-1818.

Rathmann, R.J., B.C. Bernhard, R.S. Swingle, T.E. Lawrence, W.T. Nichols, D.A. Yates, J.P. Hutcheson, M.N. Streeter, J.C. Brooks, M.F. Miller, and B.J. Johnson. 2012. Effects of zilpaterol hydrochloride and days on the finishing diet on feedlot performance, carcass characteristics, and tenderness in beef heifers. J. Anim. Sci. 90:3301-3311 10.2527/jas.2011-4375. doi:10.2527/jas.2011-4375.

Robles-Estrada, J.C., A.A. Arrizon, A. Barreras, J.F. Calderon, F. Figueroa-Saavedra, N. Torrentera, A. Plascencia, and R.A. Zinn. 2009. Effects of preslaughter withdrawal period on response of feedlot heifers to zilpaterol hydrochloride supplementation: Growth performance and carcass characteristics. J. Anim. Sci. 87:1759-1763 10.2527/jas.2008-1071. doi:10.2527/jas.2008-1071.

Roeber, D. L., R. C. Cannell, K. E. Belk, R. K. Miller, J. D. Tatum, and G. C. Smith. 2000. Implant strategies during feeding: impact on carcass grades and consumer acceptability. J. Anim. Sci. 78:1867-1874. doi:/2000.7871867x.

Roy, B.C., G. Sedgewick, J.L. Aalhus, J.A. Basarab, and H.L. Bruce. 2015. Modification of muature non-reducible collagen cross-link concentrations in bovine m. gluteus medius and semitendinosus with steer age at slaughter, breed cross and growth promotants. Meat Sci. 110:10-117 10.1016/j.meatsci.2015.07.008. doi:10.1016/j.meatsci.2015.07.008.

Scheffler, J. M., D. D. Buskirk, S. R. Rust, J. D. Cowley, and M. E. Doumit. 2003. Effect of repeated administration of combination trenbolone acetate and estradiol implants of growth, carcass traits, and beef quality of long-fed Holstein steers. J. Anim. Sci. 81:2395-2400. doi:/2003.81102395x.

Schiaffino, S., L. Gorza, S. Sartore, L. Saggin, S. Ausoni, M. Vianello, K. Gundersen, and T. Lomo. 1989. Three myosin heavy chain isoforms in type 2 skeletal muscle fibres. J. Musc. Res. and Cell Mot. 10:197-205.

Schmidt, T.B., and K.C. Olson. 2007. The effects of nutritional management on carcass merit of beef cattle and on sensory properties of beef. Vet. Clin. North Am. Food Anim. Pract. 23:151-163 10.1016/j.cvfa.2006.11.004. doi:10.1016/j.cvfa.2006.11.004.

Schneider, B.A., J.D. Tatum, T.E. Engle, and T.C. Bryant. 2007. Effects of heifer finishing impants on beef carcass traits and longissimus tenderness. J. Anim. Sci. 85:2019-2030 10.2527/ jas.2007-0004. doi:10.2527/jas.2007-0004.

Scramlin, S.M., W.J. Platter, R.A. Gomez, W.T. Choat, F.K. McKeith, and J. Killefer. 2010. Comparative effects of ractopamine hydrochloride on growth performance, carcass traits, and longissimus tenderness of finishing steers. J. Anim. Sci. 88:1823-1829 10.2527/jas.2009-2405. doi:10.2527/jas.2009-2405.

Shanks, B. C., D. M. Wulf, and R. J. Maddock. 2002. Technical note: The effect of freezing on Warner-Bratzler shear force values of beef longissimus steaks across several postmortem aging periods. J. Anim. Sci. 80(8):2122-2125. doi:/2002.8082122x.

Smulders, F.J., B.B. Marsh, D.R. Swartz, R.L. Russell, and M.E. Hoenecke. 1990. Beef tenderness and sarcomere length. Meat Sci. 28:349-363 10.1016/0309-1740(90)90048-B. doi:10.1016/0309-1740(90)90048-B.

Strickland, N.C. 1978. A quantitative study of muscle development in the bovine foetus (Bos indicus). Anat. Histol. Embryol. 7:193-205 10.1111/j.1439-0264.1978.tn00795.x. doi:10.1111/j.1439-0264.1978.tb00795.x.

Strydom, P.E., L. Frylinck, J.L. Montgomery, and M.F. Smith. 2009. The comparison of three $\beta$-agonists for growth performance, carcass characteristics and meat quality of feedlot cattle. Meat Sci. 81:557-564 10.1016/j.meatsci.2008.10.011. doi:10.1016/j.meatsci.2008.10.011.

Vestergaard, M., P. Henckel, N. Oksbjerg, and K. Sejrsen. 1994. The effect of cimaterol on muscle fiber characteristics, capillary supply, and metabolic potentials of longissimus and semitendinosus muscles from young Friesian bulls. J. Anim. Sci. 72:2298-2306. doi:/1994.7292298x. 